\title{
A MÁQUINA DO MEU MUNDO
}

\section{MY WORLD'S MACHINE}

\section{MARQUES, SONIA}

Arquiteta, Doutora, email: soniamarques51@gmail.com

\begin{abstract}
RESUMO
Quando a máquina do mundo - alegoria continuamente evocada pelos poetas - abriu-se para Carlos Drummond de Andrade, oferecendo-lhe uma "total explicação da vida", ele, que, por longo tempo, estivera na busca, declina da oferta e prossegue na estrada solitária. Espelhada neste poema que cito, ao longo deste ensaio, revisito as questões centrais para as quais busquei respostas, ao longo de uma trajetória de 41 anos, como professora e pesquisadora de Arquitetura e Urbanismo. Recusando as respostas teóricas e práticas que me foram oferecidas, bem como as que se pretendem corretivas ou alternativas, comento algumas destas questões, sobretudo à luz do que observei na recente viagem a Minas Gerais, Espírito Santo e São Paulo, entre novembro e dezembro de 2017.
\end{abstract}

PALAVRAS-CHAVE: Modernidade \& Contemporaneidade, Ensino de Projeto de Arquitetura, Crítica da Arquitetura.

\section{ABSTRACT}

When Brazilian poet Carlos Drummond de Andrade receives the visit of the World's Machine - which stands for all possible knowledge and the sum of the answers for all questions that afflict mankind - he declines the offer of endless knowledge and proceeds on his gloomy, solitary path. Taking a page from Andrade's poem quoted throughout this essay, I am revisiting essential questions for which I sought answers along my 41-year trajectory as a teacher and researcher on Architecture and Urban Planning. Rejecting obvious explanations and established practices, I reflect on several of these questions, especially in light of what I observed on a recent trip to Minas Gerais, Espírito Santo, and São Paulo in November and December 2017.

KEYWORDS: Modernism \& Contemporaneity, Architectural Design Teaching; Architectural Criticism.

\section{A MÁQUINA DO MEU MUNDO}

Pede-me a revista PROJETAR, a exemplo do que fizera a outros colegas ${ }^{1}$, um ensaio, uma reflexão situada ao final de uma trajetória profissional, longa, dedicada sobretudo ao ensino e à pesquisa. $O$ pedido, porém, encontra-me num momento de perplexidade, pouco rumo e pouco prumo, pouco aparelhada para uma escrita assertiva. Não há estado de espírito para isso. Nada há a demonstrar, desacredito, lassa, como Drummond em um poema ${ }^{2}$ que transcrevo paulatinamente, associando-o aos meus fragmentos de reflexões.

\section{E como eu palmilhasse vagamente uma estrada de Minas, pedregosa, e no fecho da tarde um sino rouco}

Novembro de 2017. Palmilho estradas de Minas, começo por Uberlândia, o segundo município mais populoso do estado, atualmente com 676.613 habitantes. O campus da UFU é agradável, algumas edificações interessantes, projetos de qualidade. De resto, a paisagem urbana geral é desoladora, no ambiente construído muito recente, edificações opulentas, às vezes ostensivas, feias. Como conseguimos projetar tão mal? Com indicadores elevados e acima da média nacional ${ }^{3}$, a cidade é o retrato de um novo Brasil que estaria "dando certo".

Estou no $12^{\circ}$ Seminário DOCOMOMO ${ }^{4}$, cuja seção brasileira vi nascer, da qual fui coordenadora nacional, em 2014, tendo participado de vários encontros internacionais, nacionais e regionais. O balanço é ambíguo. Muita coisa foi documentada, alguns jovens com um real desejo de descoberta, mas tudo se reduz à academia, não sai do círculo dos pesquisadores. Um certo déjà vu. Trabalhamos sobre questões que nós próprios criamos. Os que questionam a dinastia do Dr. Lúcio e do Oscar ou a legitimidade do autor (ou daqueles que pretendem falar em nome dele) como guia para a intervenção, o que seria uma postura dita 
típica da pós-modernidade, também não me convencem. Esta não é a função do DOCOMOMO. Talvez a nova coordenação assinale trilhas mais auspiciosas.

Entre Uberlândia e Belo Horizonte há $537 \mathrm{~km}$. Mas o percurso dura mais de oito horas, o ônibus entra e para em muitas cidades. Em Araxá, saltamos todos. Estação ideal ${ }^{5}$ para curas termais, Bandeira conhecia 0 assunto e as três moças do sabonete ${ }^{6}$. O que diria este pioneiro modernista se visse a cidade agora?

Vamos embora.

Passamos a aproximadamente trinta quilômetros de Divinópolis, gostaria de conhecer Adélia. Mas deixa estar. Chegamos em BH. Tenho um dever a cumprir: Brumadinho, oriento uma dissertação sobre Inhotim.

se misturasse ao som de meus sapatos

que era pausado e seco; e aves pairassem

no céu de chumbo, e suas formas pretas

lentamente se fossem diluindo

na escuridão maior, vinda dos montes

e de meu próprio ser desenganado,

Uma decepção, tanta fora a expectativa! Inhotim, em crise, cinquenta por cento dos funcionários desempregados é, sem dúvida, um sítio exuberante. De arquitetura, destaco dois bons projetos. Em ambos, tanto o peso da massa construída como as estratégias de acesso, marcam, de modo diferente, uma vontade de trazer o espectador ao retiro, para concentrar-se no que há de exposto. Na galeria Rio Branco, implantada levando em conta o desnivelamento do terreno, o acesso é pelo nível intermediário, que abriga uma praça coberta e espaços de apoio - sanitários e lanchonete. A força do volume, acentuada pelo revestimento em aço Corten, também chamado aço auto-patinável, pois, ao oxidar-se, cria uma pátina protetora, lembrou-me o Museu de Pierre Soulages, em Rodez ${ }^{7}$. Na galeria Andujar, - a Maxita Yano ou casa de barro como a chamaram os lanomâmi ${ }^{8}$. - o peso é dado por uma tectônica da alvenaria de tijolo muito expressiva. E a iluminação natural, sobretudo no pergolado de acesso, nos oferece uma transição envolvendo-nos progressivamente no clima da "aldeia"

No mais, apesar da arquitetura que o desfavorece, o True Rouge de Tunga avermelhou-me, como já o fizera o desvio de Cildo Meireles na Bienal, há muito, no Ibirapuera. Re-impregnada, passo à galeria Adriana Varejão, de correto projeto. O Celacanto não me provoca nem maremoto, nem terremoto.

a máquina do mundo se entreabriu para quem de a romper já se esquivava e só de o ter pensado se carpia.

Abriu-se majestosa e circunspecta, sem emitir um som que fosse impuro nem um clarão maior que o tolerável

O que escrever neste ensaio? Claudia Loureiro, que falta você me faz! Sugerem-me colegas queridos que aproveite o espaço concedido para rasgar o verbo, a exemplo de Clarice, evitando rasgar o sujeito. Disseram-me: critique a evolução da formação de maestros sem orquestras desde os anos $1970^{\circ}$, questione a performance dos atuais 466 cursos, em 27 unidades da federação e 210 cidades, lembre que, destes, só pouco mais de $10 \%$ são oferecidos por instituições públicas, mostre como esta formação mal prepara tocadores de qualquer banda safada de garagem; diga tudo o que você sempre quis dizer, agora aposentada e sem amarras. Mas para que? Inútil catarse? Houvesse alguma eficácia! E pensei em Bruno Latour: d'où viendraient les difficultés à comprendre l'action efficace? ${ }^{10}$

pelas pupilas gastas na inspeção contínua e dolorosa do deserto,

e pela mente exausta de mentar

O trem de Belo Horizonte a Vitória: 664 km, 13 horas. Passamos por Monlevade, penso no projeto de Lúcio Costa de 1934, e depois por Itabira, ai Drummond! A estrada, nesta parte de Minas, evoca uma 
modernidade sonhada, de uma liberdade ainda que tardia, sonho contemporâneo, 1789, aqui e além do Atlântico, no hexágono, que, em nossas terras, nunca chegou. Governador Valadares, outro sítio de anseios de modernidades incompletas. E as águas poluídas do rio Doce a testemunhar crimes recentes.

toda uma realidade que transcende

a própria imagem sua debuxada

no rosto do mistério, nos abismos.

E vamos chegando a cidades de nomes bonitos: Krenak, Resplendor e Aimorés. Mas de lembranças tristes. Krenak e Aimorés são sinônimos, o governo militar, de 1969 a 1972, manteve o Reformatório Krenak, na terra da etnia, para receber indígenas criminosos ou considerados de mau comportamento. Convênio firmado pela Fundação Nacional do Índio (Funai) deu à Polícia Militar de Minas Gerais a tarefa de cuidar das aldeias da região, no Vale do Rio Doce, já cobiçada à época por fazendeiros e mineradores. Quem desobedecesse às regras ficava preso. Não se trata do passado. Em 2016, dizia o Globo"11: "na terra indígena Krenak, que abriga cerca de 400 pessoas em quatro mil hectares, na margem esquerda do Rio Doce, cercas foram colocadas recentemente, parte do plano de redução de danos das empresas envolvidas no rompimento da barragem do Fundão, em Mariana (MG). A medida visa evitar que animais criados pelos indígenas, especialmente bois, bebam água do rio".

Abriu-se em calma pura, e convidando quantos sentidos e intuições restavam a quem de os ter usado os já perdera

e nem desejaria recobrá-los, se em vão e para sempre repetimos os mesmos sem roteiro tristes périplos,

Estamos em Vitória. Linda chegada, acolhida por amigos ${ }^{12}$, hospedo-me na casa pátio Marroquim, projeto do escritório homônimo, elegância e requinte, o brilho da simplicidade, com todas as qualidades do bom modernismo, diria Campello ${ }^{13}$.

convidando-os a todos, em coorte, a se aplicarem sobre o pasto inédito da natureza mítica das coisas,

Do restaurante na Enseada do Suá, avisto o Cais das Artes, projeto de Paulo Mendes da Rocha (Figura 1). Segundo uma revista ${ }^{14}$. ... numa extensa esplanada aterrada em frente ao canal que conforma a ilha de Vitória, o projeto faz um elogio desse território construído pelo monumental confronto entre natureza e construção (...) Trata-se, portanto, de uma ação arquitetônica orientada urbanisticamente no sentido de adequar história e geografia a uma desejada visão do presente, (...) Meus pobres olhos, pouco educados para esta arquitetura - considerada muito difícil para leigos, segundo um especialista da área, e que teria um profundo sentido do lugar ${ }^{15}$, segundo outro especialista - não enxergam nada disso.

Figura 1: Cais das Artes, de Paulo Mendes da Rocha. Vitória/ES.

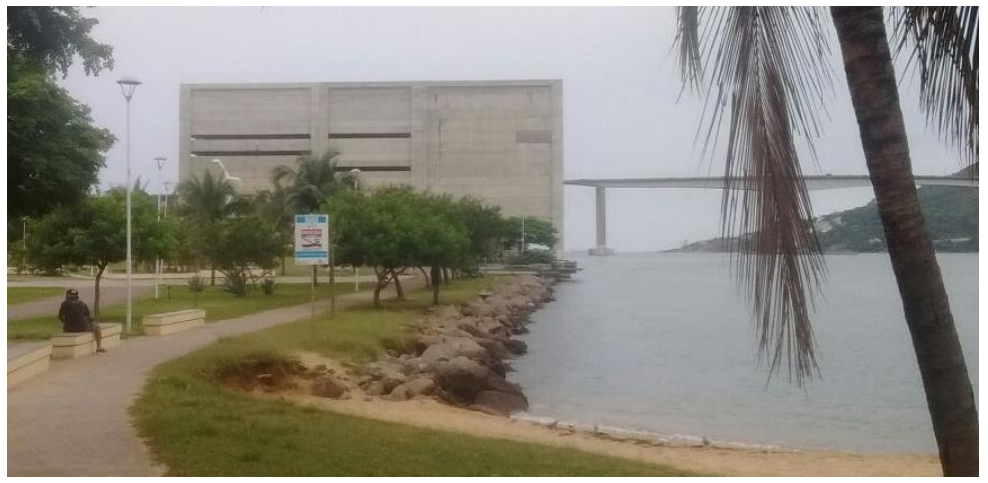

Fonte: Jean-Loic Delhaye (2017). 
assim me disse, embora voz alguma

ou sopro ou eco ou simples percussão

atestasse que alguém, sobre a montanha,

a outro alguém, noturno e miserável,

em colóquio se estava dirigindo:

"O que procuraste em ti ou fora de

O que procurei? Via o Pavilhão de Verificação de Óbitos da Faculdade de Medicina todos os dias, junto à Faculdade de Medicina, onde meu pai era professor, mas também a casa Murilo Medeiros, em Casa Forte $^{16}$, que admirava, nas raras vezes em que ia ao bairro. No bairro das Graças, onde morei, admirava a casa modernista do engenheiro Fernando Caldas (demolida) na rua das Pernambucanas e, mais ainda, a casa de Doutor Flávio Pires, dentista e rádio amador, uma versão popular de modernismo, simples, um caixote que ainda está lá, na rua Sebastião Leme, número 38 (Figura 1). Claro, o projeto da casa Fernando Almeida é superior a ambas, mas ficava um pouco mais longe, lá onde eu não ia. Mais tarde, na esquina da rua Jacobina, vi construir uma casa em modernismo popular, telhado borboleta, desmesurado, painel de azulejos com pássaros, que achei muito brega e atrasada, em relação aos meus ícones precedentes.

Figura 2: Casa Doutor Flávio Pires, Graças, Recife/PE.

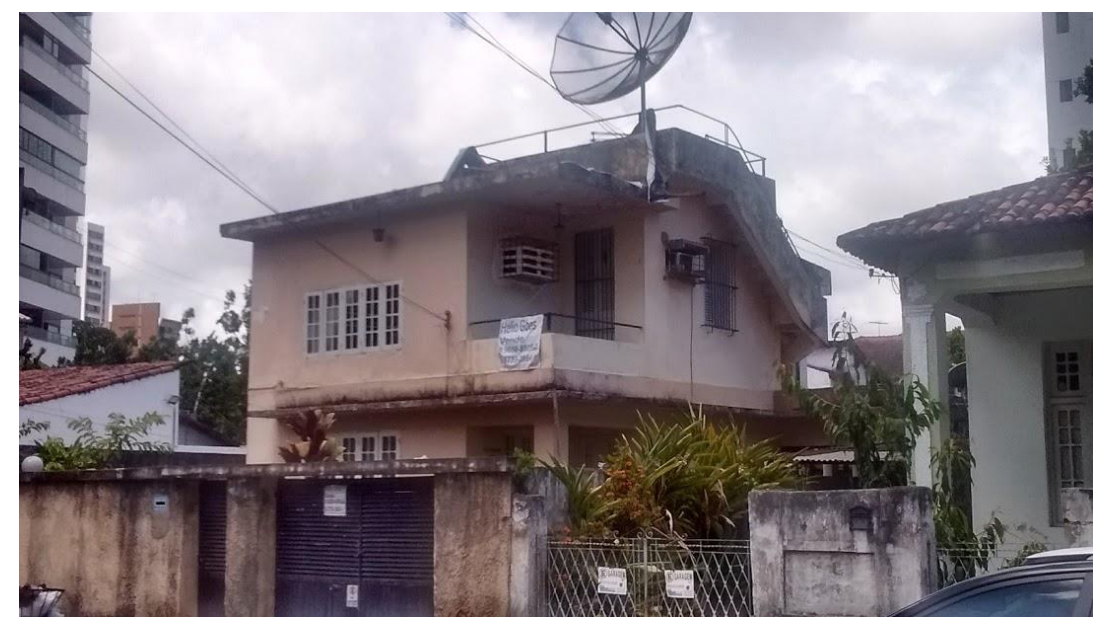

Fonte: Jean-Loic Delhaye (2017).

Como todos da minha geração, acompanhei, deslumbrada, a construção da nova capital, desejando um dia pôr meus pés naquele progresso. Eu gostava de desenhar e fui para a Escolinha de Artes ${ }^{17}$, na rua do Cupim. Nesta época, Borsoi cuidava de terminar Cajueiro Sêco e minha mãe, que tinha José Maria de Albuquerque Melo como um irmão, falava-me da oficina de litogravura que restara da Revista $O$ Norte. Adão Pinheiro e outros artistas passavam lá por casa, próximos do Movimento de Cultura Popular. Com o golpe militar de 1964, tudo mudou. Mas as conversas sobre arte e cultura continuavam, ainda que o clima fosse cada vez mais lúgubre. Assim, ouvi falar da morte de Le Corbusier, da ida de Niemeyer para Paris. Esta vivência foi decisiva para a escolha do curso de arquitetura. Em 1967, estudava na Aliança Francesa e comecei a ensinar francês no Yázigi, uma turma apenas de rapazes, adolescentes cheios de vida, pouco mais moços que eu. Entre eles, Leonardo Bittencourt.

teu ser restrito e nunca se mostrou, mesmo afetando dar-se ou se rendendo, e a cada instante mais se retraindo,

que vou pelos caminhos demonstrando, e como se outro ser, não mais aquele habitante de mim há tantos anos,

passasse a comandar minha vontade que, já de si volúvel, se cerrava semelhante a essas flores reticentes 
1968: para quem gosta de pensar e ama a liberdade a vida é difícil, no Brasil. O cursinho preparatório para o vestibular de arquitetura faliu; fui para outro, dirigido por Nélson Gesteira, engenheiro, em cujo escritório de cálculo fui trabalhar. Findas as aulas, passávamos na Faculdade de Arquitetura para ver os nossos futuros colegas. De lá, íamos ao TPN - Teatro Popular do Nordeste, também na Avenida Conde da Boa Vista. Shows de Paulinho da Viola, Naná Vasconcelos, Gil e tantos outros.

E veio o congresso da UNE, em Ibiúna e a prisão dos estudantes que admirávamos. Passei no vestibular, sem problemas, muito bem classificada. Mas, sensível a causas alheias, logo entrei na "luta de feras" para que ingressassem também os colegas excedentes - como se chamava, à época, os que ultrapassavam o número de vagas estabelecidas, mesmo que tivessem notas altíssimas, o que era o caso. Foi criada uma turma B, para os excedentes. Entramos todos na faculdade - turma A e turma B - em 1969. Em pouco, acabaria o meu entusiasmo.

em si mesmas abertas e fechadas; como se um dom tardio já não fora apetecível, antes despiciendo,

Amigas da minha geração contam-me que haviam sido ótimas alunas, desde o jardim da infância, adoravam estudar, sempre as melhores da turma, até que, passaram muito bem no vestibular de arquitetura mas, uma vez no curso, pela primeira vez na vida, haviam recebido uma nota baixa, abaixo de sete. O problema, no entanto, não era a nota. Era a impossibilidade de compreender onde estava falha e como superar ${ }^{18}$. Depois encontrei vários alunos assim, nesta mesma situação. Você não dá para isso, não tem talento, mude de curso. Os fracassados do projeto ${ }^{19}$. Pensei que fosse um fenômeno pessoal ou local, mas busquei e aprendi que era muito mais amplo. Daí ter corrido para Sociologia das Profissões, daí minhas pesquisas, desde o mestrado, até a criação do Projetar e, a seguir, a passagem para o campo das artes visuais. O caminho foi longo, árido. O deserto, por vezes salpicado dos pequenos oásis de interlocuções ricas ${ }^{20}$. Compreendi.

baixei os olhos, incurioso, lasso, desdenhando colher a coisa oferta que se abria gratuita a meu engenho.

Agora estamos em São Paulo. Meus amigos me mostram o novo bairro da zona Sul, a Chácara de Santo Antônio, almoçamos no instituto Tomie Ohtake e depois um aperitivo no terraço-jardim do hotel Unique antes do jantar. Deselegâncias cada vez menos discretas. No intervalo, fui ao Ibirapuera, lembrei das Bienais, revendo cartazes e nas entrelinhas das informações os embates dos bastidores, passeei no parque público aberto, cheio de gente de verdade, outrora parte de um sonho, como fora o DAU de Joaquim Cardozo e Luiz Nunes, como foram Pampulha e Brasília.

A treva mais estrita já pousara sobre a estrada de Minas, pedregosa, e a máquina do mundo, repelida,

se foi miudamente recompondo, enquanto eu, avaliando o que perdera, seguia vagaroso, de mãos pensas.

É hora de outros sonhos, outros projetos que transgridam a ostentação novidadeira.

\section{NOTAS E REFERÊNCIAS}

${ }^{1}$ Como Leonardo Bittencourt - UFAL e Sheila Orstein - USP.

${ }^{2}$ A Máquina do Mundo, considerado um dos mais proeminentes dentre os poemas metafísicos tardios de Drummond foi publicado em 1951 no livro Claro Enigma, editora José Olympio. O personagem é um anti-Fausto que recebe a visita da máquina com a promessa do 
saber total. A alegoria da máquina, recorrente na poesia foi utilizada, entre outros por Dante, Camões antes de Drummond e por Haroldo Campos em A Máquina do Mundo Repensada em 2000.

${ }^{3}$ Segundo dados do PNUD (Programa das Nações Unidas para o Desenvolvimento).

${ }^{4}$ Documentação e Conservação do Movimento Moderno, ONG internacional, ver https://www.docomomo.com

${ }^{5}$ cf. LIMA, G.T.N. Via de duplo sentido: Araxá cidade-balneário 1920-1940. Tese (Doutorado em História) - Pontifícia Universidade Católica de São Paulo (PUC-SP), São Paulo, 2007.

${ }^{6}$ BANDEIRA, M. Balada das Três Mulheres do Sabonete Araxá. In: Estrela da Manhã, edição original, 1936, reedição Editora Global: São Paulo, 2012.

${ }^{7}$ Projeto de 2008, dos catalães RCR arquitectes associados com o escritório Passelac \& Roques, que visitei em 2016.

${ }^{8}$ http://www.arquitetosassociados.arq.br/?projeto=galeria-claudia-andujar-inhotim-2

${ }^{9}$ Uma referência à dissertação de mestrado defendida em 1983 na UFPE. Disponível em https://issuu.com/sonia_marques/docs/mestrado

${ }^{10}$ http://www.bruno-latour.fr/sites/default/files/P-120-SACREMENT.pdf

${ }^{11}$ https://oglobo.globo.com/brasil/as-tragedias-dos-indios-krenak-18533019

${ }^{12}$ Entre eles a arquiteta Eliane Lordello, a quem agradeço a acolhida a generosa e competente interlocução intelectual, inclusive a leitura cuidadosa deste ensaio.

${ }^{13}$ CAMPELLO Glauco, O Brilho da Simplicidade, Casa da Palavra, 2001

${ }^{14} \mathrm{https}: / /$ www.archdaily.com.br/br/01-16341/cais-das-artes-paulo-mendes-da-rocha-mais-metro

${ }^{15}$ Projeto arquitetônico e a relação com o lugar nas obras de Paulo Mendes da Rocha 1958-2000. Autor, Souto, Ana Elisa Moraes. Orientador, Mahfuz, Edson da Cunha. Data, 2010. Doutorado. UFRGS.

${ }^{16}$ Do arquiteto italiano Mario Russo, ver http://www.vitruvius.com.br/revistas/read/arquitextos/11.131/3826 Eu vi o modernismo nascer... foi no Recife, Sonia Marques and Guilah Naslavsky, arquitextos, 131.02 year 11, apr. 2011 e CABRAL, Renata Campello. Mario Russo: um arquiteto racionalista italiano em Recife.

${ }^{17}$ Escolinha de Arte do Recife, fundada em 1953, por Aloisio Magalhães e Augusto Rodrigues na Rua do Cupim, onde ensinaram Ana Mae Barbosa e Thereza Carmen, entre outros, é referência em ensino de arte moderna. Seu aluno mais celebre tendo sido Gil Vicente.

${ }^{18}$ Desistiram do curso e são excelentes médicas.

${ }^{19}$ Ver os trabalhos de Jean-Pierre Chupin sobre o assunto. Ver também os escritos de Jorge Otero-Pailos que permitem fazer uma relação entre fracassados do projeto e a emergência do arquiteto-historiador, como no artigo publicado em http://vitruvius.com.br/revistas/read/arquitextos/11.125/3628, A fenomenologia e a emergência do arquiteto-historiador.

${ }^{20}$ Citar os habitantes destes oásis, ex-alunos e colegas de Arquitetura e Urbanismo, Sociologia e Artes Visuais, todos que muito contribuíram para o meu enriquecimento intelectual, seria missão de risco para a memória sexagenária que mal pode apoiar-se num Currículo Lattes sempre desatualizado. Mas registro meus agradecimentos a todos eles, inclusive àqueles associados à aventura do Projetar.

NOTA DO EDITOR (*) O conteúdo do artigo e as imagens nele publicadas são de responsabilidade do(s) autor(es). 